\title{
ECG-GATED DYNAMIC MAGNETIC RESONANCE IMAGING METHOD FOR EXAMINATION OF THE PIG HEART
}

\author{
Zs. PetrÁsi ${ }^{1}$, R. ROMVÁRI $^{1 *}$, G. BAJZIK ${ }^{1}$, B. FENYVES ${ }^{2}$, I. REPA ${ }^{1}$ and P. HORN ${ }^{1}$ \\ ${ }^{1}$ Diagnostic Institute, Faculty of Animal Science, Kaposvár University, H-7401 \\ Kaposvár, P.O. Box 16, Hungary; ${ }^{2}$ Department and Clinic of Surgery and Ophthalmology, \\ Faculty of Veterinary Science, Szent István University, Budapest, Hungary
}

(Received February 19, 2001; accepted May 17, 2001)

\begin{abstract}
A dynamic magnetic resonance imaging (MRI) method was developed for in vivo examination of the pig heart. Measurements were carried out on 15 meattype pigs of different liveweight using a $1.5 \mathrm{~T}$ equipment. Inhalation anaesthesia was applied, then data acquisition was synchronised by ECG gating. Depending on the heart rate and heart size, in each case 8 to 10 slices and in each slice 8 to 14 phases were acquired prospectively according to one heart cycle. During the postprocessing of the images the left and the right ventricular volumes were determined. The values measured at $106 \mathrm{~kg}$ liveweight are 2.5 times higher than those obtained at $22 \mathrm{~kg}$, while the ejection fractions are equal. The calculated cardiac output values were 3.51 (22 kg, 132 beats $/ \mathrm{min}$.), and 6.01 (106 kg, 91 beats $/ \mathrm{min}$.), respectively. After measuring the wall thickness, the contraction values were also determined for the septum $(70 \%)$, and for the anterior $(61 \%)$, posterior $(41 \%)$ and lateral (54\%) walls of the left ventricle. Three-dimensional animated models of the ventricles were constructed. Based on the investigations performed, the preconditioning, the anaesthetic procedure, the specific details of ECG measurement and the correct MR imaging technique were worked out.
\end{abstract}

Key words: Pig, heart, magnetic resonance imaging, ECG gating

The cardiovascular system of swine has been studied since the age of Harvey, the 18th century. From the result of these studies it is clear that the human and the porcine heart are highly analogous in terms of electrophysiological and immunological properties, the capacity to adapt to physical load and the relative heart weight values (Bowman and Hughes, 1984; Hughes, 1986; Smith et al., 1997; Crick et al., 1998). This has made the pig a very important animal model for human medical research (Parker et al., 1987; Swindle, 1992).

The selection for high lean meat percentage in the carcass plays an important role in the disadvantageous changes of the circulatory system and the heart in an animal species that has less favourable physiological characteristics (Rühl, 1971). It has been known for a long time that, of all domesticated species,

\footnotetext{
"Corresponding author; E-mail: romvari@ct1.kaposvar.pate.hu; Fax: +36 (82) 313-753
} 
the pig has the smallest heart in terms of relative heart weight, which ranges from 0.27 to 0.35 per cent (Bergmann, 1884, cit. Stünze et al., 1959). This value varies between 0.8 and $0.9 \%$ in piglets and between 0.4 and $0.5 \%$ in growing pigs (Renk, 1951). The developmental process and the performance of the heart fail to keep up with those of the skeletal musculature. Due to this fact, peripheral or central circulatory deficiency may develop, and events causing normally unimportant stress (e.g. movement of fattening pigs, veterinary treatment, grouping, hierarchical fights) can result in sudden death (Topel et al., 1968; Sybesma and Eikelenboom, 1969). Thus, already a minor physical load can lead to a substantial increase of the heart rate. Above the critical limit of 170 beats $/ \mathrm{min}$, the ventricular systole is so short timed that the onset of atrial contraction precedes the end of ventricular contraction, which in turn impairs the normal haemodynamic state. As the depots of the porcine heart are quite low, even a short period of tachycardia can lead to its exhaustion (Tóth, 1993).

From the point of view of pork production, cardiovascular diseases represent serious problems during fattening. According to Schoder et al. (1993) and Vrbanac et al. (1997), some 14 to $18 \%$ of the total number of deaths have a circulatory problem in their background. Recently many investigators have reported on similar problems in other species selected for many generations for rapid growth and high carcass meat content. In case of broilers and turkeys Shapiro et al. (1998), Martinez et al. (1998), Horn (2000) and Horn et al. (2000) have established that the relative heart weight and, consequently, the performance of the circulatory system have markedly decreased as compared to earlier genotypes characterised by a much lower growth and meat production potential.

The aim of this work was to work out an ECG-gated dynamic magnetic resonance imaging (MRI) method suitable for characterising the circulatory system of pigs of distinctly different genotypes.

\section{Materials and methods}

Measurements were carried out on 15 meat-type (Hungarian Large White $\times$ Belgian Landrace $\times$ Pietrain $\times$ Norwegian Landrace) swine of different liveweights (between 22 and $106 \mathrm{~kg}$ ). The investigations were performed at the Diagnostic Institute of the Kaposvár University using a Siemens Magnetom Vision Plus type magnetic resonance tomograph equipment of $1.5 \mathrm{~T}$ magnetic-field strength. Before the examination a pulse meter (POLAR Horse Trainer Basic) was fixed on the chest, to facilitate continuous monitoring of the changes in pulse rate. Simultaneously, ECG was carried out with an Innomed Heart Copy mobile ECG unit.

The basic condition of a successful MRI procedure is quiet general anaesthesia with as little motion as possible. This involves less risk in piglets, but 
in animals of higher liveweight or with a relatively high fat ratio, shock sensitivity and the narcotics dissolved in the fat tissue cause serious problems. Anderson (1973) published a comprehensive study on possibilities of anaesthesia in the porcine species. For routine purposes, ketamine-based narcosis was regarded as the ideal solution for many decades (Fébel and Babinszky, 1988). Since 1990, endotracheal intubation with inhalation anaesthesia has become widely known and used (Gasthuys et al., 1990; Roussi et al., 1996).

In functional heart examinations the artefact caused by movement can be avoided by cardiac gating, with quick and motion-compensating sequences (gradient echo, echo planar, snapshot Flash) (Petterson, 1998). By the ECG gating of the investigation the data acquisition has to be synchronised with the rhythmic motion of the heart. Using the ECG triggering the start of acquisition can be optionally modified related to the ECG R-wave (Stark and Bradley, 1992). As a first step of the development process, Feinberg et al. (1984) applied a flow-meter fixed on one lip which guided the MRI data acquisition and attempted to quantify the flow as well. As an alternative way, peripheral gating was used, where the plethysmograph was logged onto a finger in the investigations of Enzmann and Pelc (1993).

The first dynamic MRI examinations were described by Mansfield (1977). Highly modern imaging techniques were widely applied to determine the function of heart cavities mostly after 1980. Doyle et al. (1983) elaborated the basic methodology for the clinical applications after having tested the procedure on pigs. To determine the functional parameters of the human heart, first Longmore et al. (1985) carried out such examinations. The functional and bioenergetic consequences of infarction were studied by Zhang et al. (1996) in pigs. The ventricular mass was measured by an automatic contours detection method (Furber et al., 1998). Left ventricular contractility is decreased following myocardial infarction in the pig as established by Setser et al. (2000) by means of cine magnetic resonance imaging.

\section{Results and discussion}

The pulse was monitored continuously from the relaxed state prior to anaesthesia until the deep narcosis. Shortly before the MR examination the pulse meter was removed, as during the examination time the MRI equipment was responsible for the monitoring. The pulse registered during the total time was that according to the relaxed state. The electrocardiogram attained from the foregoing time of examination gave accurate information about the overall conditions and the anaesthetic possibilities concerning each animal.

For premedication of the animals, combined narcotics were used intramuscularly. This premedication consisted of SBH ketamine (Produlab Pharma; $12-15 \mathrm{mg} / \mathrm{kg}$ body weight) and Rometar (2\%) (Spofa; $0.05-0.1 \mathrm{mg} / \mathrm{kg}$ body 
weight). This was followed by inhalation anaesthesia through a narcotic mask, using 3 vol. \% isoflurane (Abbott Lab.), until total relaxation, when the animals were intubated and attached to a narcotic unit (Penlon evaporator, Ohmeda flowmeter). Using endotracheal intubation the difficulties (impeded respiratory movements, mostly in dorsal position) arising from the very specific porcine anatomy (i.e. tight larynx and trachea) could be avoided. Continuous deep narcosis was obtained using $1.5-2$ vol. \% Isoflurane $(0.14 \mathrm{ml} / \mathrm{min}-0.28 \mathrm{ml} / \mathrm{min}$, for piglets and fattening pigs, respectively) and oxygen. This ensured a quiet and compensated respiration and, furthermore, a waking up without any side effects. In our opinion the best solution would be an MR compatible volume-gated anaesthesia.

After having shaved the chest area of the pigs, self-adhesive electrodes (Skintact) were fixed using a contact gel. The animals were then placed into an MR-compatible special plastic container in ventral position with extended limbs, and were fixed with belts.

To obtain the proper signal strength from the electrocardiograph, different electrodes were tried out, as the relatively dense skin, connective tissue and fat are of lower conductivity. The electrodes fixed on the chest move in synchronism with the respiration, which raises the specific problem of electromagnetic induction as the cables cross the magnetic field lines. This markedly decreases the signal-to-noise ratio of the data. The only solution to avoid this was the use of a special active electrode (Bruker Medical), the sensors of which are located as the corners of a regular triangle of $5 \mathrm{~cm}$ edge length. The electrode attached to the signal cable was fixed $10 \mathrm{~cm}$ from the sternum, left, between the third and sixth ribs, the other two directed to the left olecranon between the third and sixth ribs. By this method a strong signal could be obtained even in animals of high body weight or having a thick layer of subcutaneous fat. During the imaging process the animals were continuously observed by a video camera, and their pulse and ECG were monitored. Before awakening a sedative, Acepromazin (1\%) (Albrecht, $0.25 \mathrm{mg} / \mathrm{kg}$ body weight) was applied intramuscularly.

The MR examination was conducted using ECG-gated sequences. At first, quick two-plane (sagittal and transverse) images were made to locate the heart accurately according to the co-ordinate system of the body. Subsequently, localisation images of 8 slices were taken in the sagittal, coronal and transversal planes to locate the longitudinal axis of the heart (acquisition time: 15-20 seconds). These localisation images can be seen in Fig. 1. 

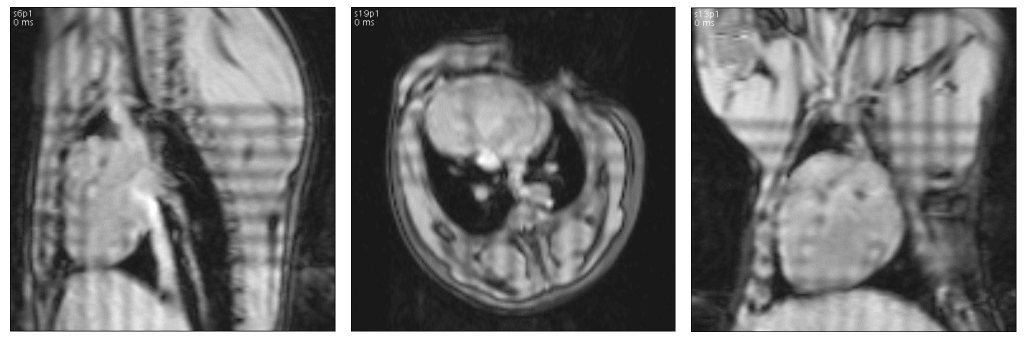

Fig. 1. Sagittal, transversal and coronal plane localisation images

After that, sagittal and coronal one-slice cine images were taken (singleslice - multiphase) according to the location of the heart. The aim of these two examination steps is to define the longitudinal and transversal axes of the heart, on which the transversal plane images are based (angulation).

The dynamic images were taken orthogonal to the longitudinal axis of the heart, from the apex to the base, covering all ventricles and atria, making prospective data acquisition (Fig. 2). In the coronal images the transversal slices covering the ventricles are marked as they cross the longitudinal axis.
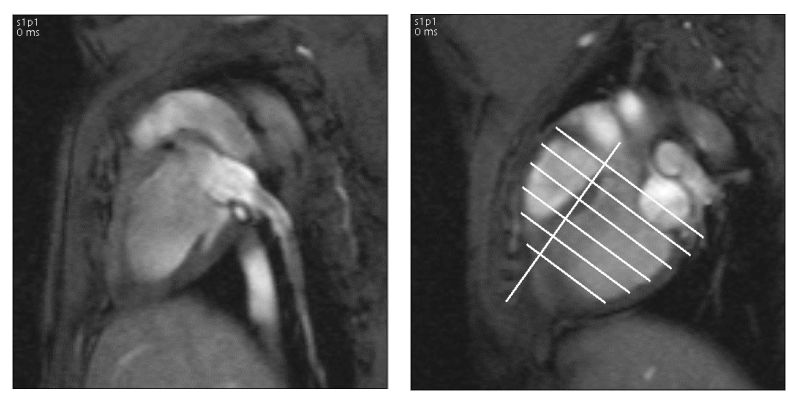

Fig. 2. Singleslice - multiphase sagittal and coronal images

The data acquisition took approx. 10-18 minutes. Depending on the heart rate and on the size of the heart, in each case 8 to 10 slices and in each slice 8 to 14 images (phases) according to one heart cycle were acquired (singleslice multiphase). The number of phases used in each case depends on the actual heart rate and the optional repetition time ( 40 or $60 \mathrm{~ms}$ ). From the 8 to 10 transversal slices representing the total heart volume in general 5 to 6 covered the ventricles (see Fig. 3). The phases applied can be characterized by the following data: TE: $6.8 \mathrm{~ms}$, TR (repetition time): $40.0 \mathrm{~ms}, \theta: 30^{\circ}$, FoV: $400-500 \mathrm{~mm}$, matrix size: $256 \times 256$ pixels, slice thickness: $9 \mathrm{~mm}$, slice gap: $0 \mathrm{~mm}$.

The MR images have been archived on optical discs. The images in Siemens Vision image format were converted under Unix OS on a SUN terminal 
and then evaluated using the special software MASS 4.0 (MR analytical software system). This software was developed by the Medical University of Leiden, especially to evaluate multiphase-multislice dynamic MR images of heart ventricles. During post-processing the contour of the ventricular epicardium and endocardium, the outline of the left ventricular papilla and the focus of the left ventricle was defined (see Fig. 4).
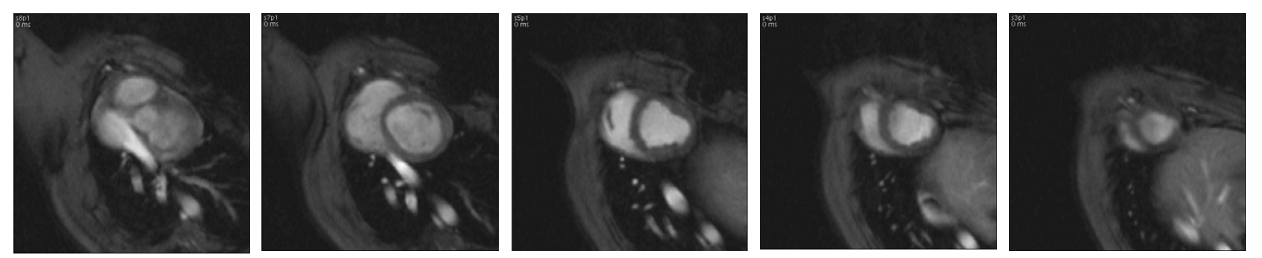

Fig. 3. Transversal slices covering the ventricles

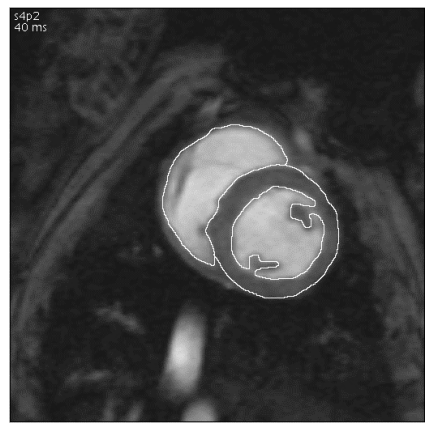

Fig. 4. Transversal image with the marking of the left ventricular endocardium and epicardium and the contour of the right ventricular endocardium

Subsequently the left and the right ventricular volume was measured. The wall thickness was measured at the septum and at the anterior, posterior and lateral walls, $9 \mathrm{~mm}$ beneath the atrioventricular valve. The data shown in Table 1 are average values measured during the heart cycle. The left ventricular mass was calculated from the regions epicardium - endocardium + papillary $1+$ papillary 2 (marked in Fig. 4) times $1.05(\mathrm{~g} / \mathrm{ml})$. The calculated ejection fraction is given as the percentage of the ratio of the stroke volume to end-diastole.

The equal values of the left and right ventricular volume imply the high accuracy of the measurement and the normal heart function. The ventricular volumes are 2.5 times higher in pigs of $106 \mathrm{~kg}$ liveweight than in those weighing 22 $\mathrm{kg}$, adding that the ejection fractions are equal. The calculated cardiac outputs are 3.51 (22 kg, 132 beats/min.), and 61 (106 kg, 91 beats/min.), respectively. 
Table 1

Some characteristic data concerning heart performance

\begin{tabular}{cccccccccccccc}
\hline $\begin{array}{c}\text { LW } \\
\mathrm{kg}\end{array}$ & $\begin{array}{c}\text { LVEDV LVESV } \\
\mathrm{ml}\end{array}$ & $\begin{array}{c}\text { LVSV } \\
\mathrm{ml}\end{array}$ & $\begin{array}{c}\text { LVEF } \\
\%\end{array}$ & $\begin{array}{c}\text { RVEDV } \\
\mathrm{ml}\end{array}$ & $\begin{array}{c}\text { RVESV } \\
\mathrm{ml}\end{array}$ & $\begin{array}{c}\text { RVSV } \\
\mathrm{ml}\end{array}$ & $\begin{array}{c}\text { RVEF } \\
\%\end{array}$ & $\begin{array}{c}\text { LVMass } \\
\mathrm{g}\end{array}$ & $\begin{array}{c}\text { Sept. } \\
\mathrm{mm}\end{array}$ & $\begin{array}{c}\text { Ant. } \\
\mathrm{mm}\end{array}$ & $\begin{array}{c}\text { Lat. } \\
\mathrm{mm}\end{array}$ & $\begin{array}{c}\text { Post. } \\
\mathrm{mm}\end{array}$ \\
\hline 22 & 51.4 & 24.4 & 27 & 52.5 & 55.7 & 28.6 & 27.1 & 48.7 & 52.1 & 7.1 & 6.1 & 6.0 & 5.0 \\
106 & 125.7 & 60.1 & 65.6 & 52.2 & 118.4 & 52.5 & 65.9 & 55.7 & 132 & 9.6 & 7.6 & 9.1 & 8.2 \\
\hline
\end{tabular}

Where: $\mathrm{LW}=$ liveweight, LVEDV = left ventricular end-diastolic volume, LVESV = left ventricular end-systolic volume, LVSV = left ventricular stroke volume, LVEF = left ventricular ejection fraction, RVEDV = right ventricular end-diastolic volume, RVESV = right ventricular endsystolic volume, RVSV = right ventricular stroke volume, RVEF $=$ right ventricular ejection fraction, LVMass $=$ left ventricular myocardial mass, Sept. $=$ septal wall thickness, Ant. $=$ anterior wall thickness, Lat. = lateral wall thickness, Post. = posterior wall thickness

The changes of the heart cycle over time are depicted in Fig. 5 at the age of 150 days. The first phase is synchronous with the ECG R-wave which is the beginning of the isometric contraction. Ventricular volume is at the maximum at this point. As the ventricular diastole ends (6th to 7th phase), the phase of isometric relaxation begins. The contraction values (septal, anterior, lateral and posterior: $70 \%, 61 \%, 41 \%$ and $54 \%$, respectively) calculated from the measured wall thickness data are characteristic of the condition of the heart musculature. Cardiomyopathy or local circulatory failures cause a functional anomaly of the muscle fibres, and decrease the contraction values. The deviation of the ventricular volume and contraction data from the normal values have great diagnostic value.

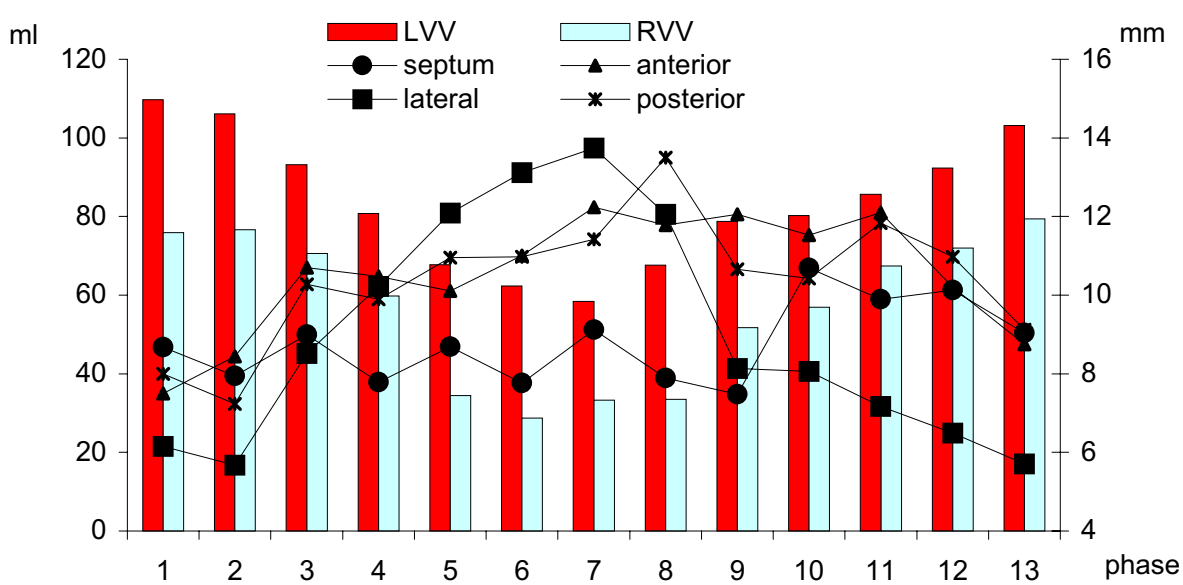

Fig. 5. Left and right ventricular volume, and changes in left ventricular wall thickness measured in different locations during the heart cycle 
The applied TR of $40 \mathrm{~ms}$ gives the best resolution attainable. To characterise the heart function, it is not necessary to follow the whole cycle; rather, it is sufficient to cover the phase from the end-diastole to the end-systole. In our routine procedure, for the right ventricle measurements were made only for the phases belonging to extreme ventricular values, to control the left ventricular stroke volume. The time of total data acquisition can be decreased by increasing the slice thickness which, in turn, impairs the image resolution. By the evaluation three-dimensional animated models (Fig. 6) of the ventricles were reproduced after pre-defined contour lines. These provide a unique opportunity for studying changes in wall thickness and those of the ventricles in motion.
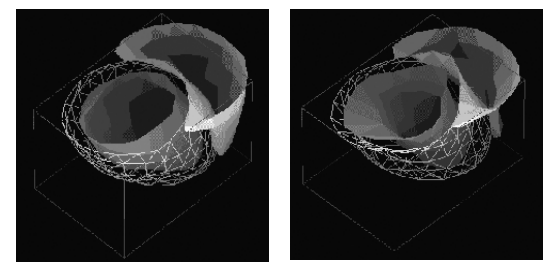

Fig. 6. Three-dimensional reconstruction of the porcine heart in the phases of end-diastole and end-systole

In this methodological study a dynamic MR imaging protocol of the porcine heart was developed. Based on the investigation of 15 animals the preconditioning, the narcotic procedure, the specific details of ECG measurement (i.e. proper signal transmission) and the correct MR imaging were worked out. On the basis of the results obtained so far, this method has proven to be well applicable for the qualitative measurement of the heart, where each investigation takes approx. 30 to 40 minutes. The method combined with a CT imaging process of the body gives a favourable opportunity for studying the skeletal musculature together with the circulatory system. This method is suitable for the examination of intensive meat-type and extensive fat-type swine from the age of weaning up to slaughter.

\section{References}

Anderson, I. L. (1973): Anaesthesia in the pig. Aust. Vet. J. 49, 474-477.

Bowman, T. A. and Hughes, H. C. (1984): Swine as an in vivo model for electrophysiologic evaluation of cardiac pacing parameters. Pacing Clin. Electrophysiol. 7, 187-194.

Crick, S. J., Sheppard, M. N., Ho, S. Y., Gebstein, L. and Anderson, R. H. (1998): Anatomy of the pig heart: comparisons with normal human cardiac structure. J. Anat. 193, 105-119.

Doyle, M., Rzedzian, R., Mansfield, P. and Coupland, R. E. (1983): Dynamic NMR cardiac imaging in a piglet. Br. J. Radiol. 56, 925-930.

Enzmann, D. R. and Pelc, N. J. (1993): Cerebrospinal fluid flow measured by phase-contrast cine MR. AJNR, 14, 1301-1307. 
Feinberg, D. A., Crooks, L., Hoenninger, J., Arakawa, M. and Watts, J. (1984): Pulsatile blood velocity in human arteries displayed by magnetic resonance imaging. Radiology 153, 177-180.

Fébel, H. and Babinszky, L. (1988): General anaesthesia in growing pigs using the combination of ketamine, fentanyl and droperidol (in Hungarian, with English abstract). Magyar Állatorvosok Lapja 43, 603-608.

Furber, A., Balzer, P., Le Jeune, J. J., Rouleau, F., Bienvenu, P., Crou'e, A., Lethimonnier, F., Jallet, P., Tadei, A. and Geslin, P. (1998): Measurement of the left ventricular mass using MRI with automatic determination of the endocardial and epicardial contours. Arch. Mal. Coeur Vaiss. 91, 863-871.

Gasthuys, F., Pollet, L., Simoens, P., Lauwers, H. and De Leay, J. J. (1990): Anaesthesia for fluorescein angiography of the ocular fundus in the miniature pig. Vet. Res. Commun. 14, 393-402.

Horn, P. (2000): Breeding and keeping aspects of poultry production (in German). Arch. Tierz. Dummerstorf 43, Sonderheft, 106-110.

Horn, P., Sütő, Z., Kustosné Pőcze, O., Gyenis, J. and Mihók, S. (2000): Growth, feed conversion and eviscerated parameters of 1999's vs. 1960's turkeys when fed "typical" 1967 and 1999 turkey diets (Preliminary report) (in Hungarian). IIIrd International Poultry Breeding Symposium, Kaposvár, pp. 1-19.

Hughes, H. C. (1986): Swine in cardiovascular research. Lab. Anim. Sci. 36, 348-350.

Longmore, D. B., Klipstein, R. H., Underwood, S. R., Firmin, D. N., Hounsfield, G. N., Watanabe, M., Bland, C., Fox, K., Poole-Wilson, P. A. and Rees, R. S. (1985): Dimensional accuracy of magnetic resonance in studies of the heart. Lancet 1 (8442): 1360-1362.

Mansfield, P. (1977): Multiplanar image formation using NMR spin echoes. J. Phys. C. Solid State Phys. C10, L55-58.

Martinez, L. L. A., Miller, M. W., Jeffrey, J. S. and Odom, T. W. (1998): Echocardiographic evaluation of cardiac structure and function in broiler and Leghorn chickens. Poult. Sci. 77, 1045-1050.

MR Analysis Software System (MASS) version 4.0, Leiden University Medical Center and MEDIS Medical Imaging Systems, 1994-2000.

Parker, G. W., Michael, L. H. and Entman, M. L. (1987): An animal model to examine the response to environmental stress as a factor in sudden cardiac death. Am. J. Cardiol. 60, 9-14.

Petterson, H., ed. (1998): The Encyclopedia of Medical Imaging, Physics, Techniques and Procedures. The NICER Institute, Oslo.

Renk, W. (1951): The nucleus development, the heart muscle cell fibres and hypertrophy of pig heart (in German). Dtsch. Tierärztl. Wschr. 58, 385-387.

Roussi, J., André, P., Samama, M., Pignaud, G., Bonneau, M., Laporte, A. and Drouet, L. (1996): Platelet functions and haemostasis parameters in pigs: absence of side effects of a procedure of general anaesthesia. Thromb. Res. 81, 297-305.

Rühl, B. (1971): Weight, fibre thickness and number of nuclei in heart muscle and their relation to bodyweight and skeletal muscle weight in 205-day-old pigs of five breeds (in German). Zbl. Vet. Med. A. 18, 151-173.

Schoder, G., Maderbacher, R., Wagner, G. and Baumgartner, W. (1993): Causes of losses on a pig production unit. Dtsch. Tierärztl. Wschr. 100, 428-432.

Setser, R., Henson, R. E., Allen, J. S., Fischer, S. E., Wickline, S. A. and Loren, C. H. (2000): Left ventricular contractility is impaired following myocardial infarction in the pig and rat: assessment by the end systolic pressure-volume relation using a single-beat estimation technique and cine magnetic resonance imaging. Ann Biomed Eng 2000 May, 28, 484-494.

Shapiro, F., Nir, I. and Heller, D. (1998): Stunting syndrome in broilers: effect of stunting syndrome inoculum obtained from stunting syndrome affected broilers, on broilers, Leghorns and turkey poults. Poultry Sci. 77, 230-236.

Smith, A. C., Knick, B., Gillette, P. C. and Swindle, M. M. (1997): A technique for conducting noninvasive cardiac electrophysiology studies in conscious swine. J. Invest. Surg. 10, 25-29. 
Stark, D. D. and Bradley, W. G. (1992): Magnetic Resonance Imaging. Volume One. Second Edition. Mosby-Year Book, Inc., St. Louis, USA.

Stünze, H., Teuscher, E. and Glaus, A. (1959): Systematic studies on the hearts of domestic animals. The Pig (in German). Zbl. Vet. Med. 6, 640-654.

Swindle, M. M. (1992): Swine as models in biomedical research. Iowa State University Press, Ames, Iowa 50010.

Sybesma, W. and Eikelenboom, G. (1969): Malignant hyperthermia syndrome in pigs. Neth. J. Vet. Sci. 94, 155-161.

Topel, D. G., Bicknell, E. J., Preston, K. S., Christian, L. L. and Matsushima, C. Y. (1968): Porcine Stress Syndrome. Mod. Vet. Pract. 49, 59-60.

Tóth, J. (1993): Veterinary Anaesthesiology (in Hungarian). Mezőgazda Kiadó.

Vrbanac, I., Balenovic, T., Pavesic, R., Valpotic, I. and Zidar, V. (1997): The reasons for mortality of fattening swine in intensive swine production (in Croatian). Stocarstvo 51, 243-251.

Zhang, J., Wilke, N., Wang, Y., Zhang, Y., Wang, C., Eijgelshoven, M. H., Cho, Y. K, Murakami, Y., Ugurbil, K., Bache, R. J. and From, A. H. (1996): Functional and bioenergetic consequences of postinfarction left ventricular remodeling in a new porcine model. MRI and 31P-MRS study. Circulation 94, 1089-1100. 